\title{
A Content Analysis: Environment Themes and Tools in Newspapers Advertisements
}

\author{
Lecturer Levent ÖZKOÇAK \\ Anadolu Üniversitesi-TURKEY \\ Faculty of Communication Science - Departmant of Public Relations and Advertising \\ leozkocak@anadolu.edu.tr \\ Assistant Professor Yavuz TUNA \\ Anadolu Üniversitesi-TURKEY \\ Faculty of Communication Science - Departmant of Communication \\ yavuzt@anadolu.edu.tr
}

\begin{abstract}
A growing number of consumers actively seek environmentally friendly products. A newly discovered "green" consumer, the latest environmentally friendly products only to discover that too many products advertised claims to be "clean" and "green" for the environment. While this clearly is not the case today, producers are claiming more and more that their products are environmentally friendly.
\end{abstract}

The study described here was undertaken to assess the degree to which magazine advertisements depicted environmental tools on products. Analyses were conducted on which environmental issues were emphasized and the extent to which producers' advertisements on the best sellers newspapers in June, July and August of 2009. Advertisements will choose on Hürriyet, Sabah and Posta newspapers. The reason of the choosing is the best sellers newspapers on the dates which had been mentioned.

\section{Introduction}

In developed countries increasingly reflects a growing interest in environmental health, leading many to consider more ecologic products. In this condition, firms are developing various methods and products amenable to environmental demands and mandates. According to this developments in consumers' product choose and lifestyles, firms started to communicate environmental mesages in advertising tools into business opportunities (Grillo et al. 2008). Some firms believed that green communication is an essential tool to communicate environmental and are attempting to give a green identity and/or image to their products. In this communication climate, green advertising is becoming increasingly common (or popular) in today's society and across product categories and sectors. (Crane 2000). 
According to Anderson and Hansen (2004), consumers will choose the green products which are comparable priced. This king of product selection will come to gether emotional consumers with brands which have green company image overtime.

\section{Green Advertising/Green Claims}

Green marketing and consumer behavior researchs had tried to defined consumer segments who are environmentalist and their purchase characteristics. The researchers have showed the links between demographic, psychographic, consumers' attitudes, personality, and benefits have demostrated by many studies toward environmental behavior. (Davis, 1993; Ellen et al., 1991; Granzin \& Olsen, 1991; Shrum et al., 1995).

Some factors affecting environmentally behaviors were identifed by researchers: Ellen (1991) claims that consumer believes are enough to make a difference. On the other hand Davis (1993) paid attention to environmental claim specificity and emphasis. At the same time Davis believes that consumers point out the vague claims and create positive perceptions to real and truth environmental messages. According to Davis, claims should be concrete the environmental benefits and characteristics on the message. Kangun, Carlson, and Grove (1991) indicate that specific and vague claims can distinguish by consumers.

Green advertising in both television and print media is defined as any ad that meets one or more of the following criteria (Banerjee, Gulas \& Iyer., 1995):

1. Explicitly or implicitly addresses the relationship between a product/service and the biophysical environment.

2. Promotes a green lifestyle with or without highlighting a product/service.

3. Presents a corporate image of environmental responsibility.

Greenwashing: In the minds of consumers and the media, green behaviors are getting more impotrant and common because of manipulated advertising. While the consumers are making purchase decisions, the products are which percieved as "green" getting more acceptable (Phillips, 1999). By this means, companies have recognized the opportunity of capitalize on consumers' desire for environmentally conscious products (Carlson, Grove, \& Kangun, 1993). Although research has examined the truthfulness of environmental messages, there has been little theoretical reasoning offered for why these messages might be perceived as deceptive by consumers. 


\section{Using Typologies, Codes and Format}

In this study, we used three type of mesurement elements while explaining the environmental advertisements tools and themes: 1-environmental audits, 2-Carlson, Grove and Kangun's claim types and 3-print advertising format

\section{Environmental Auditing}

Although there appears to be no universally accepted environmental auditing definition, one of the most widely accepted, by businesses, and quoted definition of environmental auditing in the UK, and the one used almost verbatim in EMAS (Eco-Management and Audit Scheme)comes from the 1989 International Chamber of Commerce (ICC) position paper on environmental auditing (International Chamber of Commerce, 1989). 'A management tool comprising a systematic, documented, periodic and objective evaluation of how well environmental organisation, management and equipment are performing with the aim of helping to safeguard the environment by (Hillary, 1998):

(i)

facilitating management control of environmental practices;

(ii)

assessing compliance with company policies, which would include meeting regulatory requirements.'

\section{Environmental Audit Types}

Environmental audit types had been inspired by T. V. Ramachandra and Shruthi Bachamanda's research which had prepared for Energy and Wetlands Research Group. In this study, advertisements will be consider as they described follow:

Liabilities Audit is often conducted as a prelude to gaining insurance cover and as a means of demonstrating the regulatory compliance.

- Compliance Audit is the most common form of environmental audit that is carried out, it is a verification process whereby the facility establishes the extent to which it is complying with the environmental legislation, regulations, emission limits, etc.

- Operational risk liability audit concentrate on the potential frequency and consequence of environmentally damaging activities in the various functions of the process. Compliance with regulation does not necessarily reduce liability due to operational risks.

- Acquisition audits assess the liabilities due to contaminated land and building remediation costs. 
- Health and safety audits normally form part of Health, safety and Environment (HSE) audit and involve assessment of adequacy of personal protective equipments (safety, shoes, goggles, helmets, etc.), emergency preparedness and disaster management plans.

Management Audit pays considerable attention to management systems as they are a guide to how effectively and efficiently the operations runs

- A corporate audit is initiated by the main Board of a parent company and is concerned with the organisation structure, roles and responsibilities, policy implementation, awareness and communication. It is carried out as a reassurance to the main Board that their aims and objectives are being implemented throughout the corporate structure.

- Management systems audit are carried out to check the systems against the policy and standards such as British standard 7750 or ISO 14001.

- Policy audit is carried out to review and reassess the relevance of the policy in the light of developments (legal, technical, financial) within the organisation and outside.

- Issues audit is carried out to establish environmental management plan and targets.

Activities audit cover auditing of select technical and management issues.

- Environmental site audit examines all aspects of the facilities performance with respect to the environment. It combines most of the elements of other types of environmental assessment and when undertaken in depth involve considerable time and cost.

- The waste audits are of two types. The first identifies and quantifies waste streams and is a precursor to both waste minimisation programmes. The second type assesses waste management practice and procedures.

- Product audits cover several aspects of their environmental impacts through design, manufacture, use and disposal. Such audits are pre-requisites for identifying environmentally friendly products for "Green labelling".

- Cross boundary audits assess activities, which cut across departments or business units. Transport and supply chain are such examples.

\section{Format for Print Advertising}

In print advertising, the key format elements are the visual(s), headlines, subheads, body copy, slogans, logos and signitures. Copywriters can correlate the visual, headline and subhead to the attention step of the creative pyramid. The interest step typically corresponds to the subhead and the first paragraph of the body copy. Body copy handles credibility and desire, and the action step takes place with the logo, slogan and signiture block. We can show the componenets od print advertisind as folow (Arens, 1999): 
Headlines

The headline contains the words in the leading position in the advertisement - the words that will be read first anda re situated to draw the most attention. That's why headlines usually appear in larger type than other parts of the ad.

\section{Subhead}

The subhead is an additional smaller headline that may appear above the headline or below it. A subhead above the headline, called a kicker, is often underlined. Subheads may also appear in body copy. Subheads are usually set smaller than the headline but larger than the cody cop yor text. Subheads are important for two reason: most people read only the headline and subheads, and subheads usually support the interest step best

\section{Body Copy}

The advertiser tells the complete sales story in the body cop yor text. The body copy copmries the interest, credibility, desire and often even the action steps. It is a logical continuation of the headline and subheads, set in smaller type. Body copy covers the features, benefits, and utility of the product and services.

\section{Slogans}

Many slogans begin as successful headlines. Slogans have two basic purposes: to provide continuty to a series od ads in a campaign and the reduse an advertising message strategy to a brief, repeatable, and memorable positioning statements. Through continuous use, they become standart statements, not just in advertising but for sales people and company employees.

\section{Seals, Logos, and Signitures}

A seal is awarded only when a product meets standards established by a particular organization. Science these organizations are recognized authorities, their seals provide an independent, valued endorsement for the advertiser's product. Logos and signature cuts are special designs of the advertiser's company or product name. They appear in all company ads and, give the product individualty and provide quick recognition at the point of purchase. 


\section{Figure1: Attention Pyramid in Print Advertising}

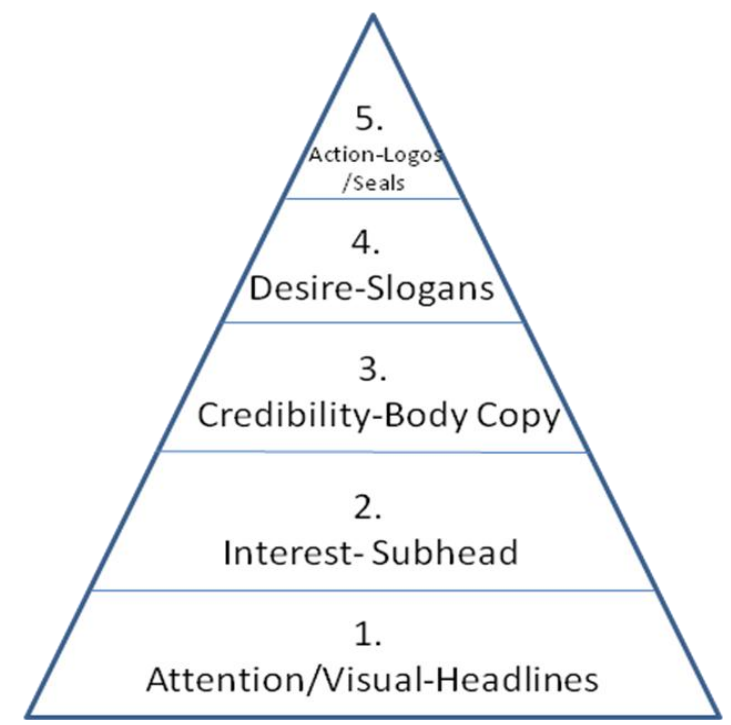

Reference: Arens, W.F. (1999). Contemporary Advertising. McGraw-Hill, International Adition, p:382

\section{Carlson, Grove and Kangun's claim types}

In this measurement element, claim types (Carlson, Grove and Kangun, 1993) which is also called Matrix Method Approach, consists of claim type and the presence of misleading and/or deceptive content among the claims. According to this approach types had been considered its contents:

\section{Types of Environmental Advertising Claims}

Product Orientation: The claim focuses on the environmentaily friendly attributes that a product possesses.

Example: This product is biodegradable."

Process Orientation: The claim deals with an organization's internal technology, production technique and/or disposal method that yields environmental benefits.

Example: "Twenty percent of the raw materials used in producing this good are recycled."

Image Orientation: The claim associates an organization with an environmental cause or activity for which there is broad-based public support.

Example (a): "We are committed to preserving our forests."

Example (b): "We urge that you support the movement to preserve our wetlands."

Environmental Fact: The claim involves an independent statement that is ostensibly factual in nature from an organization about the environment at large, or its condition. 
Example: "The world's rain forests are being destroyed at the rate of two acres per second."

\section{Misleading/Deceptive Categories of Environmental Advertising Claims}

Vague/Ambiguous: The claim is overly vague or ambiguous; it contains a phrase or statement that is too broad to have a clear meaning.

Example: "This product is environmentally friendly."

Omission: The claim omits important information necessary to evaluate its truthfulness or reasonableness.

Example: "This product contains no CFCs." (when in fact it contains other environmentally harmful chemicals)

False/Outright Lie: The claim is inaccurate or a fabrication.

Example: "This product is made from recycled materials." (when in fact it is not)

\section{Research Questions}

As green advertising has been gaining more and more importance recently, researchers are wondering how its applications are implemented. In this respect, research questions have been formed as follows:

1. What is the role of environmental audit systems in green advertising?

2. How misleading/deceptive and claims are used in environmental advertising claims?

3. At what attention level are environmental advertising given?

\section{Method}

The method of content analysis is used to measure how environmental audit systems are used in green advertising. Together with this method, coders will also evaluate how claims are applied. Particular attention was devoted in our research design to the criteria of objectivity, systematization, sampling methods, and reliability that are used to ascertain the excellence of content analysis research (Kassarjian 1977).

First of all, in this research, which resources are going to be used to obtain the environmental advertisements is determined. In this respect, samples obtained from Hurriyet, Sabah, and Posta newspapers within the period of June-August, 2009. These newspapers had the highest number of prints within this period. Newspapers' circulation reports had got from YaySat distribution agency. 
Table1: Newspapers' Circulation ${ }^{1}$

\begin{tabular}{|l|c|l|c|}
\hline ZAMAN* & 789.807 & 700.481 & 648.612 \\
\hline POSTA & 521.445 & 517.823 & 545.127 \\
\hline HÜRRIYET & 461.309 & 491.016 & 492.985 \\
\hline SABAH & 341.148 & 332.822 & 362.679 \\
\hline
\end{tabular}

Table 2: Data Distributions in Newspapers

\begin{tabular}{lcccc} 
& June & July & Agust & TOTAL \\
\hline \hline HURRIYET & 2120 & 2089 & 1857 & $\mathbf{6 0 6 6}$ \\
SABAH & 1425 & 1312 & 1272 & $\mathbf{4 0 0 9}$ \\
POSTA & 1189 & 1141 & 1106 & $\mathbf{3 4 3 6}$ \\
Total & $\mathbf{4 7 3 4}$ & $\mathbf{4 5 4 2}$ & $\mathbf{4 2 3 5}$ & $\mathbf{1 3 5 1 1}$ \\
\hline
\end{tabular}

After determining which environmental advertisements are going to be studied, the next step is to train coders about this research. Three post-graduate students from department of Public Relations and Advertising, Faculty of Communication Science, Anadolu University are the coders. The coders have been trained on environmental audits, environmental advertising claims, and print advertising attention levels. After the training, the coders were asked to code the advertisements sample with respect to subject and purpose.

\section{Data Collection}

As mentioned above, the sample has been obtained from the newspapers that had the highest number of prints within the sample period. The contents of 13511 advertisements have been searched for whether statements about environmental audits, environmental symbols, and environmentalist concepts and themes are present. Advertisements within the sample period have been obtained by using "PR Net m-suite Beta v1.0" (http://msuite.prnet.) program which our department is a member of. It is possible to virtually reach all the news and advertisement contents with this program. According to the search results, the number of environment, environmentalism, and environmentally focused social advertisements is only 55. Finding have been evaluated based on these 55 advertisements. The frequency distributions of the goods and services categories of environmental advertisements and sectors are given in Table 3 and Table4, respectively. The content analysis of the attention level of environmental

\footnotetext{
'Zaman newspaper has not been considered because of it's distribution differences from other newspapers. Zaman circulation is counted according to it's members.
} 
advertisements has not been implemented, and coders were asked to sort statements about environment with respect to the region that they were seen in.

Table3: Products or Sevices

\begin{tabular}{|cc|c|c|c|}
\hline & & Frequency & Valid Percent & Cumulative Percent \\
\hline Valid & product & 50 & 90.9 & 90.9 \\
& service & 5 & 9.1 & 100.0 \\
& Total & 55 & 100.0 & \\
\hline
\end{tabular}

Table4: Product/services chategories

\begin{tabular}{|cc|c|c|c|}
\hline & Frequency & Valid Percent & Cumulative Percent \\
\hline Valid & automobile & 18 & 32.7 & 32.7 \\
& Bank & 4 & 7.3 & 40.0 \\
home & 18 & 32.7 & 72.7 \\
combi & 2 & 3.6 & 76.4 \\
fuel-oil & 5 & 9.1 & 85.5 \\
softdrink & 2 & 3.6 & 89.1 \\
electronic & 4 & 7.3 & 96.4 \\
candy & 1 & 1.8 & 98.2 \\
other & 1 & 1.8 & 100.0 \\
Total & 55 & 100.0 & \\
\hline
\end{tabular}

\section{Findings}

\section{Reliability and Assignment of Claims}

An intercoder reliability coefficient described in Perreault and Leigh (1989) was calculated for the judges' evaluations of ad claims for each typology. This statistic is sensitive to reliability differences which arise from varying the number of classification categories and is considered to be superior to other traditional and more widely used meastires of interjudge reliability such as Cohen's Kappa (Perreault and Leigh 1989). Coefficient scores of .87 and .89 were obtained for the claim type and misleading deceptive typologies and score of .84 was obtained for environmental audits.

\section{Differences Among Categories}

When the contents of the advertisement claims have been analyzed, components of the advertisements have been divided as product, process and image. The component of 
environmental fact has been emphasised very little. In the component of misleading/decetive claims, vague/ambiguous claims have gotten all the votes (n.15), and no other components have been observed. The vague/ambiguous claims have been observed to be divided into the process and image components. When we look at the ratios of the votes for the promises of the process (n.21) and image (n.15) and the vague/ambiguous (21/7 and 15/7), the advertisement claims' persuasiveness or deceptiveness is at worring levels. Although the sample size is so small that it cannot be even expressed as a percentage, it gives us a clue about the current condition of green advertising.

Table5: Relation of Misleading/Deceptive and Claims

\begin{tabular}{|c|l|l|l|l|l|}
\cline { 3 - 6 } \multicolumn{2}{c|}{} & \multicolumn{5}{c|}{ Advertising Claims } \\
\cline { 2 - 6 } \multicolumn{2}{c|}{} & $\begin{array}{c}\text { Product } \\
(\mathrm{n}: 18)\end{array}$ & $\begin{array}{c}\text { Process } \\
(\mathrm{n}: 21)\end{array}$ & $\begin{array}{c}\text { Image } \\
(\mathrm{n}: 15)\end{array}$ & $\begin{array}{c}\text { Env. Fact } \\
(\mathrm{n}: 1)\end{array}$ \\
\hline \multirow{3}{*}{$\begin{array}{c}\text { Misleading/ } \\
\text { Deceptive }\end{array}$} & $\begin{array}{l}\text { Vague/ } \\
\text { ambiguous(15) }\end{array}$ & 1 & 7 & 7 & 0 \\
\cline { 2 - 7 } & $\begin{array}{l}\text { Omision } \\
(0)\end{array}$ & 0 & 0 & 0 & 0 \\
\cline { 2 - 7 } & Falce/ & & & 0 & 0 \\
\hline
\end{tabular}

On the other, when we analyzed the advertisements in terms of environmental audits, it is not hard to conclude that the audit themes are centered around the component of activities audit. We can argue that the result of having 26 advertisements in this audit is due to the producers' willingness to emphasise the sensitivity of their products to the environment. However, when we look at the contents and themes of the advertisements, we see that the "saving" is the most emphasised aspect. That is, advertisements" "cheap product" statements and green theme combination motivates the consumers to contribute to the environment by staying in their own budget limits To summarize, at this level it is about personal budget. On the hand, we see that compliance audit supports this analysis. Along with the economic promises, the content of advertisement includes the message that the rules about enverimental legislation, regulations, emission limits are complied by the institutions or the corporations. The number of advertisements in the management audits component (n.11) gives us an idea about the institutions' or the corporations' level of awereness of social responsibility especially given the fact that the environmental problems are brougth up during the summer. In summary, the 
results show that the advertisements in the sample chosen, are designed according to compatibility of the goods and services to the level of environmental sanctions.

Table6: Environmental Audits in Advertisements

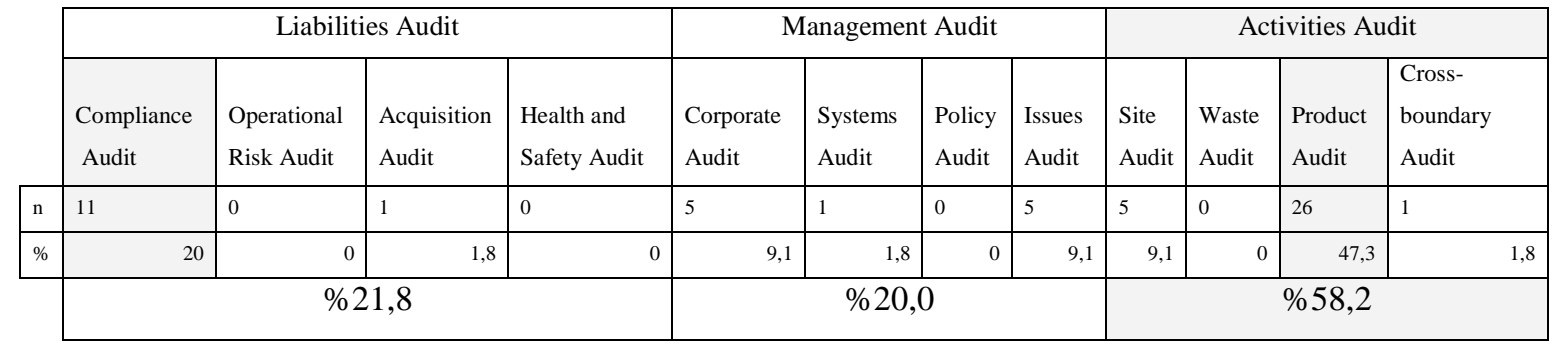

At the advertising attention level which has been mentioned in research questions, messages were very nearly hide. Environmental advertisements are placed 3rd, 4th and 5th in the attention pyramid. This finding shows us the corporates give more attention their product images then their corporate images.

Table7: Attention Levels of Claims and Statements

\begin{tabular}{|r|rr|rrr|r|}
\hline \multicolumn{7}{|c|}{ Attention area } \\
\hline Area 1 & Area 2 & Area 3 & Area 4 & Area 5 \\
\hline n $\%$ & n $\%$ & n $\%$ & n & $\%$ & n $\%$ \\
\hline
\end{tabular}

\begin{tabular}{|c|c|c|c|c|c|c|c|c|c|c|c|c|}
\hline \multirow{3}{*}{ Coder } & 1 & 19 & 15 & 18 & 14 & 34 & 27 & 30 & 23 & 27 & 21 & \\
\hline & 2 & 19 & 16 & 18 & 15 & 42 & 35 & 23 & 19 & 17 & 15 & \\
\hline & 3 & 20 & 16 & 22 & 18 & 34 & 28 & 27 & 22 & 19 & 16 & \\
\hline & & 58 & & 58 & & 110 & & 80 & & 63 & & Total: 369 \\
\hline & & & 15,6 & & 15,6 & & 30,0 & & 21,4 & & 17,4 & Total: 100 \\
\hline
\end{tabular}

\section{Conclusion}

Suprisingly, researchers have found 55 environmental advertisements in 13511 advertisements. In spite of growing interest in environmental advertising in western culture, we withnessed the level of environmental advertesment as a number in our country in first step. According to this number of advertising, it is very hard to generalize the findings all over the environmental advertisements. But in 55 advertisements, it is possible to find some presumptions for future or present stuation in this advertising sector. On the other hand, we have seen the mesages as personal bugdet or economy. Expecially disposal statements are directing the consumers to expense for disposal way, not for he environment. Also, this 
statements or mesages are the evidences for he procuders as an economic, not environmentalist. It is possible to say that environmentalist approachs or statemensts are so mousy or hidden by looking the data in attention levels of claims and statements. On the other hand Davis' belief about that "consumers point out the vague claims and create positive perceptions to real and truth environmental messages" should be consider at the level of misleading/deceptive message in 55 advertisements. At the condition of lack of evrironmental advertisements, this level of misleading/deceptive claims will make less believeable environmental advertisement in our country. This consequence will affect the real envronmetalist corporations' communication effort.

\section{References}

Anderson, R. and E. Manscn. (2004). Determining Consumer Preferences for Eeolabeled Forest Products: An Experimental Approach. .1. of Forestry $\mathrm{IO} 2(4): 28-32$.

Arens, W.F. (1999). “Contemporary Advertising”. McGraw-Hill, International Adition, p:382

Banerjee, S., Gulas, C. S. \& Iyer, E. (1995). Shades of Green: A Multidimensional Analysis of Environmental Advertising. Journal of Advertising, Volume XXIV, Number 2

Carlson, A., Grove, S. J., \& Kangun, N. (1993). A content analysis of environmental advertising claims: A matrix method approach. Journal of Advertising, 22(3), 27-39.

Crane, A. (2000). Facing the backlash: Green marketing and strategie reorientation in the 19Ws. Journal of Strategic Marketing. 8(3):277-296.

Davis, J. J. (1993). Strategies for environmental advertising. Journal of Consumer Marketing, 20, 19-36.

Ellen, P. S., Wiener, J. L., \& Cobb-Walgren, C. (1991). The role of perceived consumer effectiveness in motivating environmentally-conscious behaviors. Journal of Public Policy and Marketing, 10, 102-11

Fischer, C., Parry, I., Aguilar, F. \& Jawahar, P. (2005). Corporate Codes of Conduct: Is Common Environmental Content Feasible?. Resources fot the future Conducted for the Foreign Investment Advisory Service of the World Bank Group. Discussion Paper 05-09.

Ginsberg, J.M. and P. Bloom. (2004). Choosing the right green marketing strategy. MIT Sloan Management Review. 1(46):79-84.

Granzin, K. L., \& Olsen, J. E. (1991).Characterizing participants in activities 
protecting the environment: A focus on donating, recycling, and conservation behaviors. Journal of Public Policy and Marketing, 10, 1-27

Grillo, N., Tokarczyk, J., \& Hansen, E. (2008). Green advertising developments in the U.S. forest sector: A follow-up. Forest Products Journal Vol. 58. NO. 5

Hillary, R. (1998). Environmental Auditing:Concepts,MethodsandDevelopments International Journal of Auditing Int. J. Audit. 2: 71-85

Kangun, N., Carlson, L., \& Grove, S. J. (1991). Environmental advertising claims: A preliminary investigation. Journal of Public Policy and Marketing, $10,47-58$.

Kinnear, T. C, Taylor, J. R., \& Ahmed, S. A. (1974). Ecologically-concerned consumers: Who are they? Journal of Marketing, 38, 20-24.

Meyers-Levy, J., \& Sternthal, B. (1993). A two-factor explanation of assimilation and contrast effects. Journal of Consumer Research, 30, 359-368.

Meyers-Levy, J., \& Tybout, A. M. (1989). Schema congruity as a basis for product evaluation. Journal of Consumer Research, 16, 39-54.

Manrai, L. A., Manrai, A. K., Lascu, D.N., Ryans, J. K. Jr.(1997). How Green-Claim Strength and Country Disposition Affect Product Evaluation and Company Image. Psychology \& Marketing Vol. 14(5):511-537

Ottman, Jacquelyn (1992), "Sometimes, Consumers Will Pay More to Go Green," Marketing News, 26 (July 6), 16.

Perreault, William D. and Laurence E. Leigh (1989), "Reliability of Nominal Data Based on Qualitative Judgments," Joumal of Marketing Research, 26 (May), 135-148.

Phillips, L. E. (1999). Green attitudes. American Demographics, 21, 46-47.

Ramachandra, T. V. \& Bachamanda, S. (2007), "Environmental Audit of Municipal Solid Waste Management” Energy and Wetlands Research Group, Centre for Ecological Sciences Indian Institute of Science, Bangalore

Shrum, L. J., McCarty, J. A., \& Lowrey, T. M. (1995). Buyer characteristics of the green consumers and their implications for advertising strategy. Journal of Advertising, 24, 71-82. 